\title{
REAL-TIME ATMOSPHERIC MONITORING OF URBAN AIR POLLUTION USING UNMANNED AERIAL VEHICLES
}

\author{
QINGYUE WANG \\ Graduate School of Science and Engineering, Saitama University, Japan
}

\begin{abstract}
Unmanned aerial vehicles (UAVs), or Drones, have recently begun to appear frequently in the television, newspapers and social media for their applicability in various fields of science. Although UAVs have been used in a wide range of atmospheric science, there are few reports of using UAVs for lower layer atmospheric observation available. In my laboratory, harmful black carbon (BC) in ambient particulates was determined based on the observation results of harmful chemicals in the lower boundary layer and atmospheric conditions using UAVs. The ambient particulates in the lower layer atmosphere based on heights can be measured by UAVs at the optional location. In this paper, I want to report the lower layer atmospheric observation of ambient particulates with their chemical species for the first time in Japan. The data transfer devices were loaded into UAVs for the transformation of the results measured at different heights during 2018 in order to develop real-time observations of $\mathrm{PM}_{2.5}$ and $\mathrm{PM}_{10}$ in the lower layer atmosphere of the suburban and urban areas of Saitama city, Japan. Air pollutants transported from the urban areas of metropolitan Tokyo were determined from the real-time results of measurements in the vanity in the morning, noon and afternoon. High concentrations of $\mathrm{PM}_{2.5}$ and $\mathrm{PM}_{10}$ were observed around noon in the rural area of Yorii-machi, Saitama prefecture on December 5, 2017 which might be influenced by the polluted air mass from the urban atmosphere. It is clear that different air pollution phenomena can be observed easily by using UAVs real-time atmospheric monitoring. Keywords: unmanned aerial vehicles (UAVs), drone, ambient particulates, $P M_{2.5}, P M_{10}$, black carbon, real-time monitoring, Saitama, Japan.
\end{abstract}

\section{INTRODUCTION}

In recent years, increasing attention has been paid to air pollution by fine particles in the urban atmosphere owing to various harmful effects of those particles on human health. Atmospheric pollutants discharged from anthropogenic sources as emissions of the gaseous substance and ambient fine particles of $\mathrm{PM}_{2.5}$ (particulate matter with a $50 \%$ cut-off aerodynamic diameter $<2.5 \mu \mathrm{m}$ ) [1], the radioactive materials released by the accidents of the nuclear power plants and the chemical plants. Moreover, pollen grains [2], yellow sand dust, volcanic explosion, and a brush fire are also the origins of air pollution. Atmospheric pollutants that emitted from natural and anthropogenic sources can change the composition of ambient air affecting air quality and human health [3].

In Asian countries, severe air pollution phenomena were found with rapid economic development and urbanization during the last several decades [4]-[7]. It is essential to develop methods using unmanned aerial vehicles (UAVs) for the determination of atmospheric pollutants in the lower layer atmosphere or the place where a person cannot go easily. At the same time, UAVs can be used for the observation of the spread mechanism, the source contribution and the generation mechanism of atmospheric pollutants with the vertical distribution.

In this study, my research team has developed several unmanned aerial vehicles (UAVs) and used them for atmospheric monitoring to examine real-time variations and vertical distribution of air pollutants associated with anthropogenic activities or long-range transportation in the lower boundary layer. To investigate the contribution of the chemical components of the traffic emission [6] associated with toxicity of the airborne particulate 
matter, I have especially used those UAVs and determined the vertical distribution of $\mathrm{PM}_{2.5}$, ozone $\left(\mathrm{O}_{3}\right)$, BC caused by diesel exhaust particles (DEPs) and different carbonaceous particles $(\mathrm{OC} 1 \sim \mathrm{OCx})$ of ambient particulate matter $\left(\right.$ as $\left.\mathrm{PM}_{2.5}\right)$ at the urban roadside site in Saitama city and background site of Saitama prefecture, Japan.

\section{MATERIAL AND METHODS}

\subsection{Sampling sites}

The study was conducted in the Saitama prefecture located in the central Kanto region of Japan having a population of more than one million. Two sites viz. roadside of the city route 463 (Main prefectural road with high traffic volumes of both diesel and gasoline powered around 21,000 vehicles per weekdays) in Saitama city near the metropolitan Tokyo and background site located in the rural area of Yorii-machi in Saitama prefecture, Japan were chosen for observing air pollution.

\subsection{Unmanned aerial vehicles (UAVs)}

Several UAVs of Model EX1100SA and Model ZION QC730 (Fig. 1) embedded with payload computer were designed and made by Enroute Co., Ltd., Japan. Another Model SA888 was designed and built by Saitama University and Iyobeshoji Co., Ltd., Japan. Although the Ridge Hawk controller has the power to compute and multi-task simultaneous functions, it was built to be energy efficient to minimize battery usage during flights. The computer consists of $4 \mathrm{MB}$ of flash memory, a 12-bit A/D converter with 8 input channels, two RS232 channels, a hardware watchdog, a real-time clock and 512 bytes of RAM. During the flights of all UAVs automatically following the GPS system, we can send commands to the computer to control and change the data download feed, each payload instrument and the sensors mentioned in next sections.

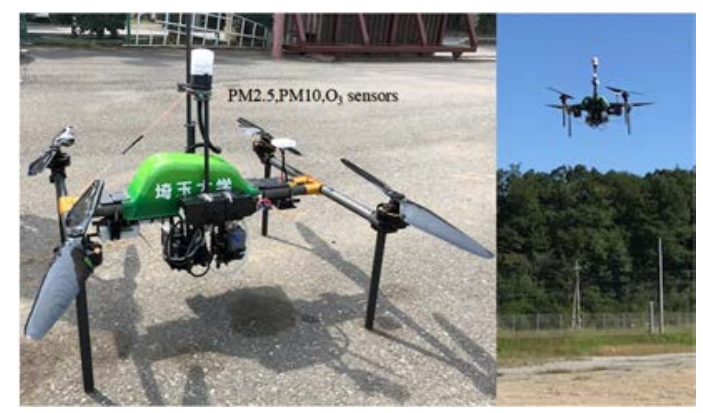

Figure 1: A basic unmanned aerial vehicles (UAVs).

The part order containing within the UAVs loading, airborne particulate sensors of $\mathrm{PM}_{2.5}$ and $\mathrm{PM}_{10}$ including two particle counters (Shibata Scientific Co., Tokyo, Japan) and real-time pollen grains counter equipment were made at the same time. In order to set on all the UAVs of Model EX1100SA, Model ZION QC730 and Model SA888, the connection parts of the all the models were also designed and improved. We had miniaturized each measuring machine module, confirmed for $10 \%$ weight saving of all the UAVs and made them of about $10 \mathrm{~m} / \mathrm{s}$ of survival wind speed to load into UAVs easily. 


\subsection{Airborne particulate sensors for $\mathrm{PM}_{2.5}$ and $\mathrm{PM}_{10}$}

Ambient particulate measurement using personal particle sensors of Model LD-6N2 (Shibata Scientific Co., Ltd., Japan) (https://www.sibata.co.jp/products/products17/), is modular in design and can be quickly installed and removed from the UAVs payload bay (Fig. 2) evaluated by Saitama University. The package is powered by the batteries (USB power supply from the same package powered by Li ion battery unit of minipump) for the duration of the flight up to 10 hours [7].
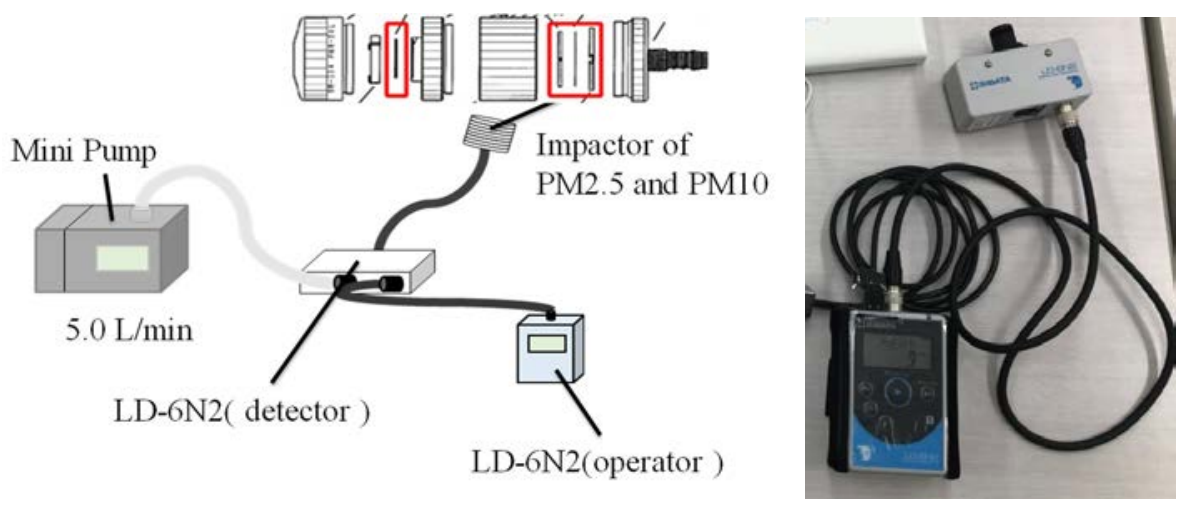

Figure 2: Personal particles sensor (Model LD-6N2) with an impactor of $\mathrm{PM}_{2.5}$ and $\mathrm{PM}_{10}$.

The aerosol package includes a passively pumped isokinetic inlet of minipump (Model MP-N $\sum$ II, Shibata Scientific Co., Japan) to bring air and particles into the module. An optical particle counter is also under development for the package powered by Li ion battery unit as the field deployment. The operation displays LED indicator for sampling air and features integrated flow measurement functions have been shown in Fig. 2.

The LD-6N2 has a quick response time, grows particles in a butanol-saturated flow and counts particles in different diameter size ranges with the modifications were implemented to address the high-vibration environment of the UAVs. $\mathrm{PM}_{2.5}$ and $\mathrm{PM}_{10}$ concentrations were also characterized and determined by their impactor and sampling size-selected particles from differential sensors designed by Saitama University [8]-[9] and also developed and hand made by Shibata Scientific Co., Japan.

\subsection{Real-time determination of the carbonaceous particles with a $\mathrm{PM}_{2.5}$ microCYCLONE}

I used the carbonaceous particle monitors (Model AE51 and Model MA 200, AethLabs, Ltd., USA, https://aethlabs.com/microaeth/ma200/overview) for the determination of carbonaceous particles. MA200 monitor is compact, real-time, wearable five-wavelength UV-IR BC monitors with 15 sampling location automatic filter tape advance system allowing up to 2-3 weeks of continuous measurements. The mass concentrations can be detected by light absorbing carbonaceous particles in a sampled aerosol. The instruments have five analytical channels each operating at a different wavelength $(880 \mathrm{~nm}, 625 \mathrm{~nm}, 528 \mathrm{~nm}$, $470 \mathrm{~nm}$ and $375 \mathrm{~nm}$ ) [10]. Measurement at $880 \mathrm{~nm}$ is interpreted as the concentration of BC [11]. Measurement at $375 \mathrm{~nm}$ is interpreted as ultraviolet particulate matter (UVPM) indicative of carbonaceous particles like wood smoke, tobacco, biomass burning and DEPs. 
In this paper, I have defined those carbonaceous particles as BC, DEPs and different organic carbon $(\mathrm{OC} 1 \sim \mathrm{OCx})$. The MA series instruments have several important advancements. The instrument automatically controlled the advance of the tape material, moving to a new unused spot when required. This allowed the instrument to run continuously for multiple weeks or months without human intervention. Five-wavelength optical engine enables discrimination between organic and elemental particles which is helpful in source identification when measuring different aerosols. The MA series also features the special loading compensation method, which in real-time measures and adjusts for differing optical properties of particles of varying age and composition. For a particle size cut point of $\mathrm{PM}_{2.5}$ $\mathrm{BC}$, the flow rate of the microAeth needs to be set to $50 \mathrm{~mL} / \mathrm{min}$. If the flow rate of the microAeth is set to $100 \mathrm{~mL} / \mathrm{min}$, the microCYCLONE will provide a particle size cut point of 1.6 microns in diameter shown in Fig. 3. Therefore, BC measurements can be carried out with the corresponding particle size selective cut point of the microCYCLONE at that flow rate.

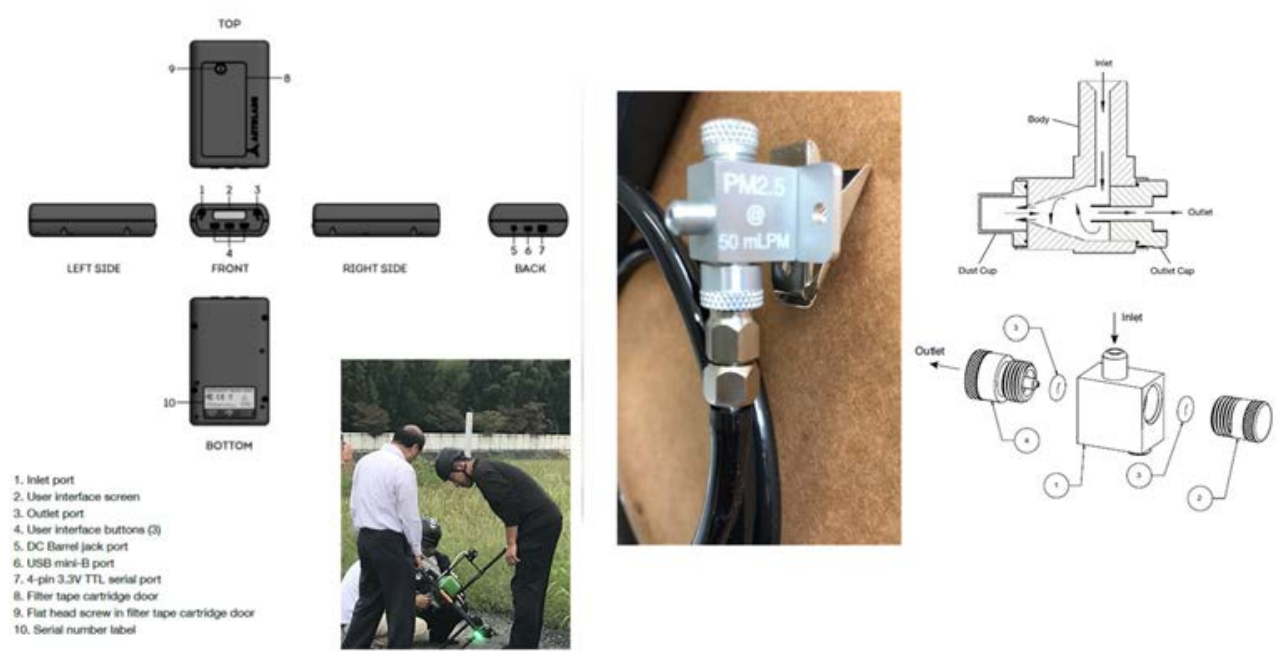

Figure 3: MA 200 carbonaceous particle monitors with a special $\mathrm{PM}_{2.5}$ microCYCLONE.

\subsubsection{Real-time determination of ambient $\mathrm{O}_{3}$}

Portable $\mathrm{O}_{3}$ monitor was used in my study. It enabled accurate real-time surveying of common air pollutants, all in an ultra-portable, handheld air quality monitor (Series 500, Aeroqual Ltd., New Zealand, https://www.aeroqual.com/product/series-500-portable-airpollution-monitor). Data were stored on board the Series 500 with a maximum 8,188 records available. To download the data a USB cable was supplied for connection to PC. Free PC software provided with the Series 500 taken the data and represented that in a chart or table view. Data were downloaded and viewed in excel.

The monitor can also operate in control mode. Upper and lower control limits can be easily set directly on the display. Using the $0-5 \mathrm{~V}$ output the Series 500 can be used to switch on or off an externally connected device, such as an $\mathrm{O}_{3}$ generator, or system in the presence of a predetermined level of $\mathrm{O}_{3}$ gas. By selecting the optional wall-mount bracket and plugging in main power the Series 500 was effectively able to act as a fixed monitor as well as a handheld portable device (Fig. 4). 


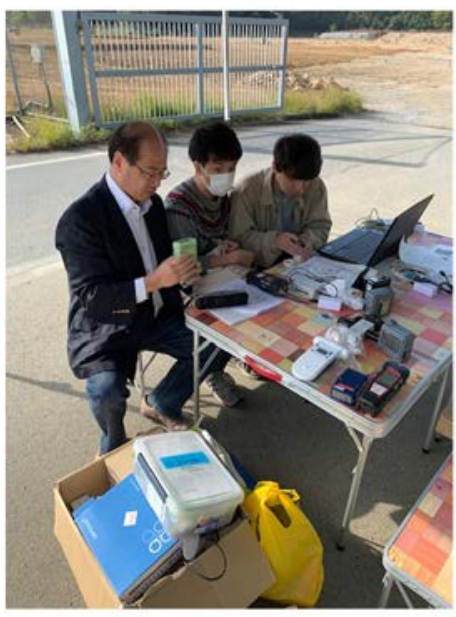

Preparation

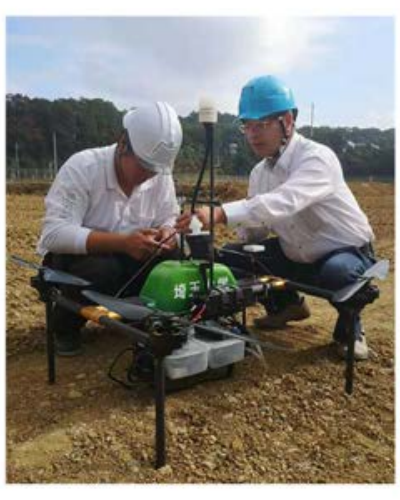

Setting and adjustments

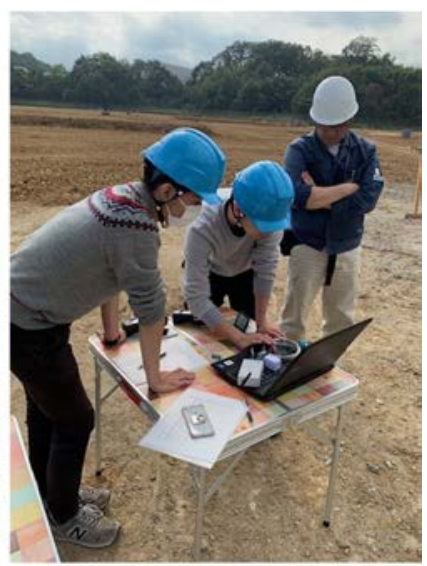

Real time data transmission

Figure 4: Observation using UAVs with the sensors of $\mathrm{PM}_{2.5}, \mathrm{PM}_{10}$, and $\mathrm{O}_{3}$ at Yorii-machi rural site, Saitama prefecture, Japan on November 15, 2018.

\section{RESULTS AND DISCUSSION}

\subsection{The real-time variations of $\mathrm{PM}_{2.5}$ and $\mathrm{PM}_{10}$ concentrations and their patterns}

During the last decade, increasing attention has been paid to fine particles such as $\mathrm{PM}_{2.5}$ in the urban atmosphere owing to the various harmful effects on human health [6]. $\mathrm{PM}_{2.5}$ can penetrate more deeply into the lungs and may reach the alveoli causing serious respiratory diseases. Motor vehicles exhaust is one of the main sources of $\mathrm{PM}_{2.5}$ in the urban atmospheric environment. Therefore, we have used UAVs for the first time in Japan to study the spread mechanism of atmospheric pollutants, the source contribution of urban atmospheric pollutants in this article.

In the case of a flight in lower boundary layer up to $140 \mathrm{~m}$, I found out that its inclination was one beyond $/ 100 \mathrm{~m}$ clearly $1{ }^{\circ} \mathrm{C}$ in the temperature profiles in the low-rise sky from the low layer around $70 \mathrm{~m}$. When flight over $100 \mathrm{~m}$ of the ground level, one below $/ 100 \mathrm{~m}$ went down about $1{ }^{\circ} \mathrm{C}$, and it means that the atmosphere was weak stability even in the low layer of $100 \mathrm{~m}$. The stronger atmosphere stability was found over $100 \mathrm{~m}$ with a weak inversion layer formed. Therefore, the atmospheric pollutants were concentrated by the pollution accumulation because of the weather condition disadvantageous to the spread of the atmospheric pollutants in the lower boundary layer during winter.

The ambient particulate measurement was carried out using the personal particle sensors in Yorii-machi, Osato-gun, Saitama prefecture on December 5, 2017 is shown in Fig. 5. Since the contaminant air masses were transported from the urban area in the Tokyo metropolitan area, the real-time results of measurement of $\mathrm{PM}_{2.5}$ and $\mathrm{PM}_{10}$ to a suburb were determined from morning to afternoon of the day. As shown in Fig. 5, it was found out that the influence of short time high concentrated atmospheric pollution occurred. After that the pollution phenomena were also determined again in the afternoon. 


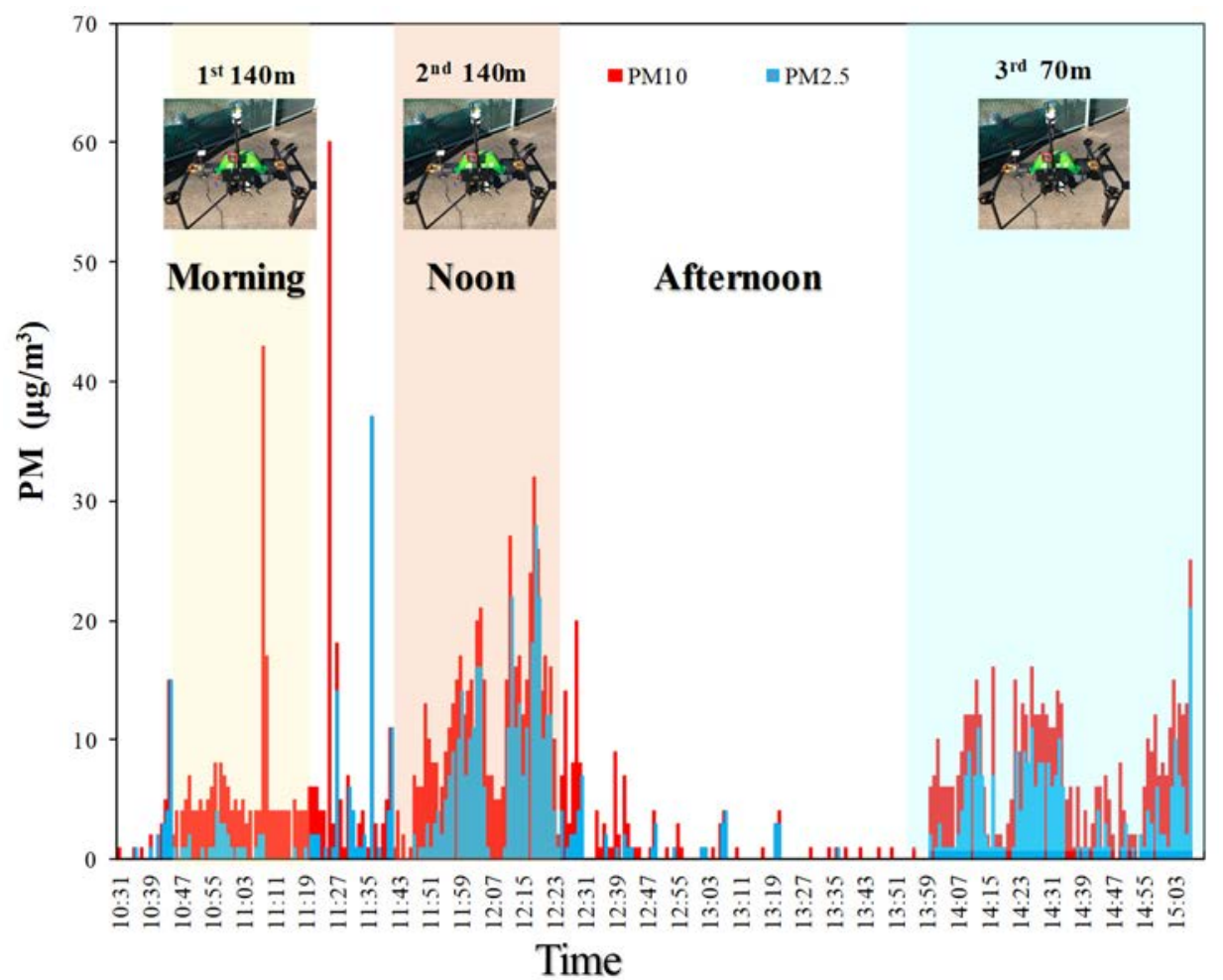

Figure 5: Real-time determination of $\mathrm{PM}_{2.5}$ and $\mathrm{PM}_{10}$ using UAVs with the personal particle sensor.

\subsection{Real-time concentrations of $\mathrm{O}_{3}$ and $\mathrm{PM}_{2.5}$ in $140 \mathrm{~m}$ atmospheric layer}

As shown in Fig. 6, the concentrations of $\mathrm{O}_{3}$ and $\mathrm{PM}_{2.5}$ were increased in the $140 \mathrm{~m}$ atmospheric boundary layer over ground level suggesting that secondary particles contribute considerably as one of the pollutants in Saitama, Japan. $\mathrm{NO}_{3}$ is usually present as $\mathrm{NH}_{4} \mathrm{NO}_{3}$ in the atmosphere. During the winter season, the concentration of $\mathrm{NO}_{3}$ was significantly increased due to diesel exhaust which is two times higher than summer might influence the pollution in the urban atmosphere.

3.3 Real-time variations and vertical distribution of carbonaceous components associated with anthropogenic activities

Diesel exhaust contains substantially more particulate matter than gasoline-fuelled vehicle exhaust and the use of diesel-powered vehicles is leading to the deterioration of air quality in urban areas.

As given in Fig. 7, real-time mass-weighed variations of carbonaceous components were determined during a sampling campaign period in 2018. At the same period, real-time vertical distribution of $\mathrm{BC}$ caused by DEPs was mainly determined in $\mathrm{PM}_{2.5}$ of the lower boundary layer shown in Fig. 8. 

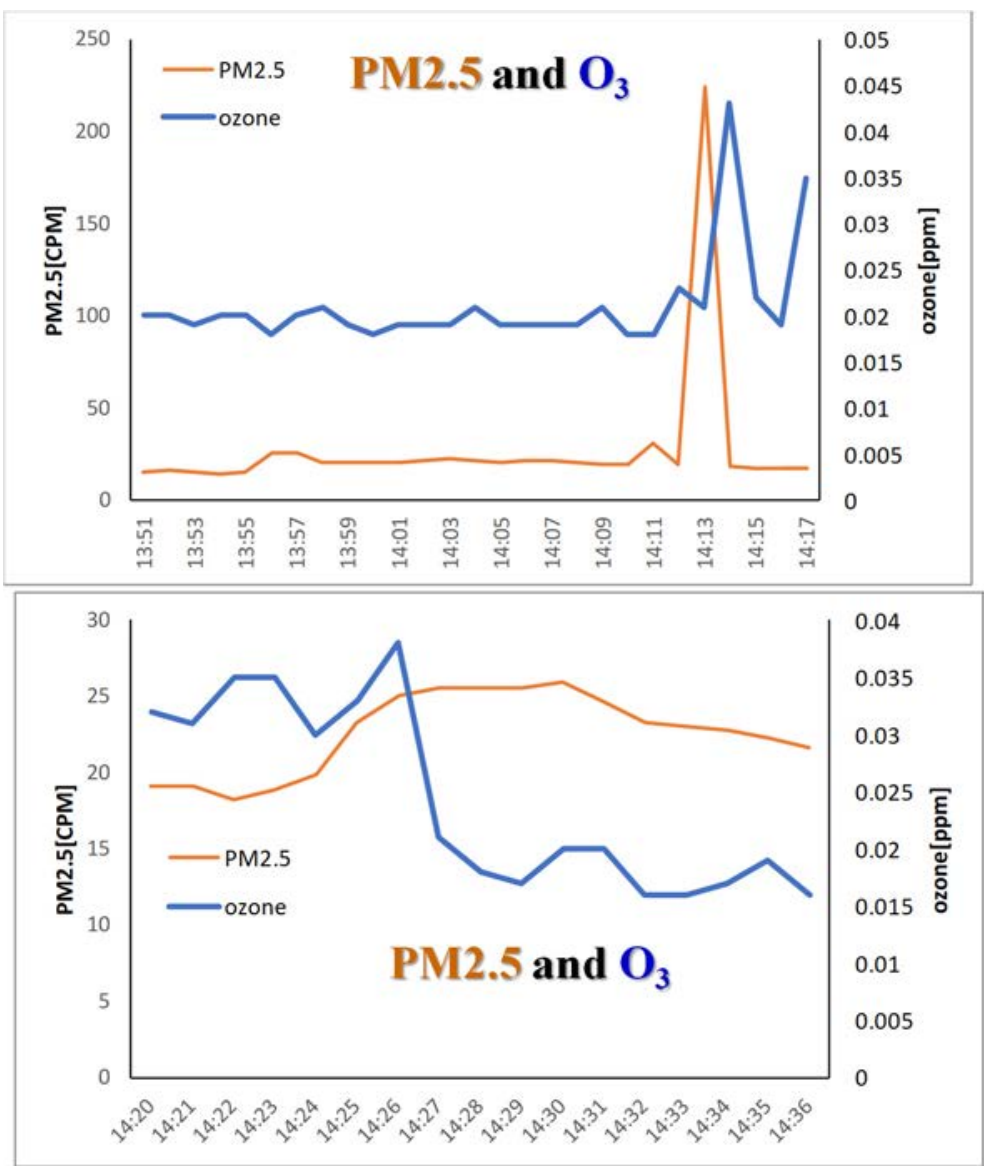

\section{Time}

Figure 6: Real-time determination of ambient $\mathrm{O}_{3}$ in $140 \mathrm{~m}$ atmospheric layer over the ground level in a background site.

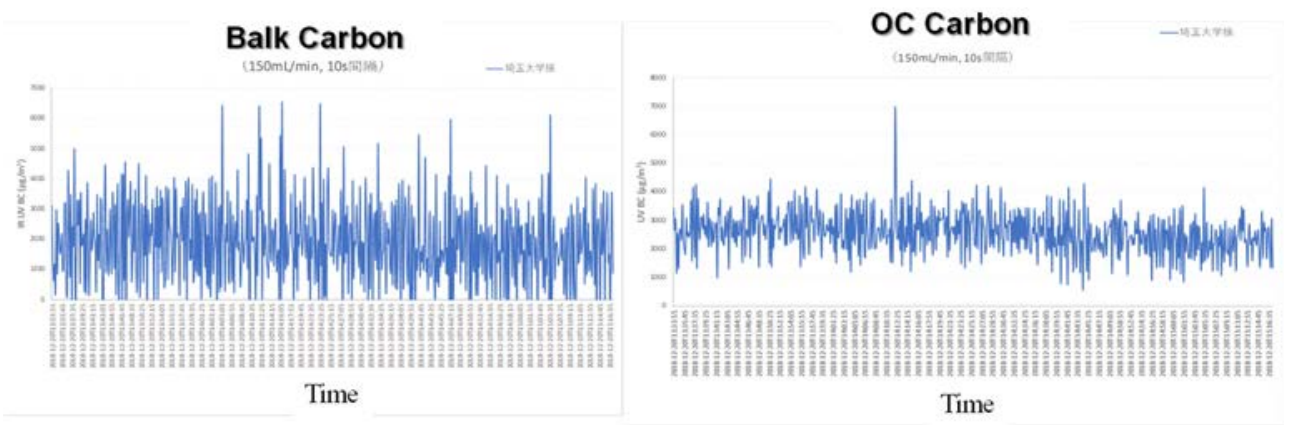

Figure 7: Real-time variations of carbonaceous components during a sampling campaign period in 2018. 


\section{Real time vertical distribution}

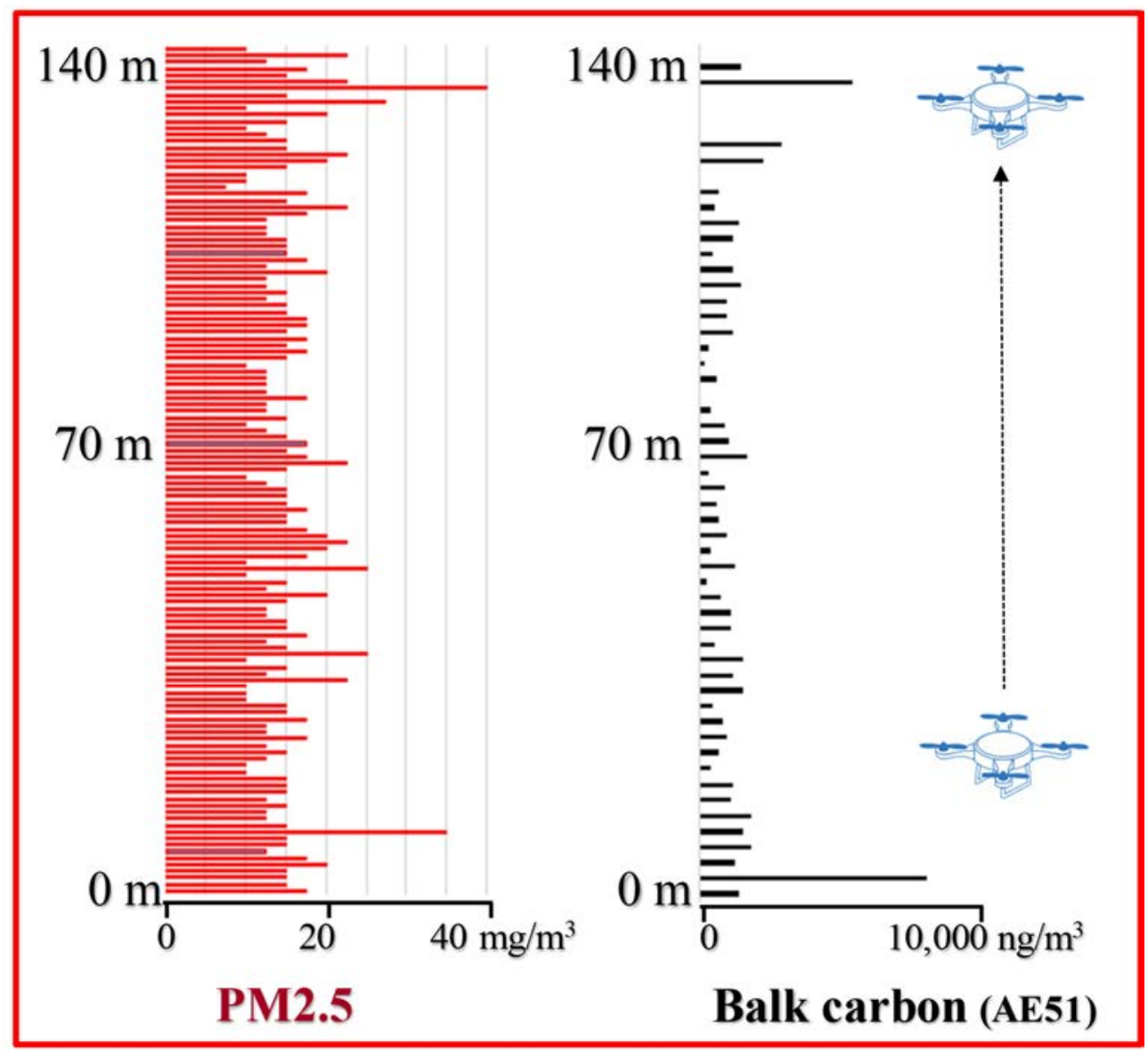

Figure 8: Real-time vertical distribution of $\mathrm{BC}$ and $\mathrm{PM}_{2.5}$ of the lower boundary layer during a sampling campaign period in 2018.

The high contributions of BC, DEPs and the different organic carbonaceous components (OC1 OCx) were observed in $\mathrm{PM}_{2.5}$ during the periods when the wind was coming mainly from the roadside toward the sampling flight site presented in Fig. 9. Therefore, I strongly believe that the contribution of carbonaceous components could be attributed to motor vehicle emissions. Moreover, the concentrations of several chemical components such as BC and $\mathrm{OC} 1 \sim \mathrm{OCx}$ at the roadside were markedly lower on the weekend than during the week. This reduction could be due to the reduction in the number of diesel-powered vehicles on the weekend. The difference was marked in the case of the $\mathrm{BC}$ concentrations, though the $\mathrm{OC} 1 \sim \mathrm{OCx}$ concentrations were closer between weekend and weekday. Some species of particulate polycyclic aromatic hydrocarbons (PAHs) were mainly derived from motor-vehicle or petroleum combustion in summer and from coal and biomass combustion in winter [6]. The high molecular weight (HMW) PAHs containing five-ring PAHs and six-ring PAHs were determined in the fine particles of $\mathrm{PM}_{2.5}$ as the components of $\mathrm{BC}$. 


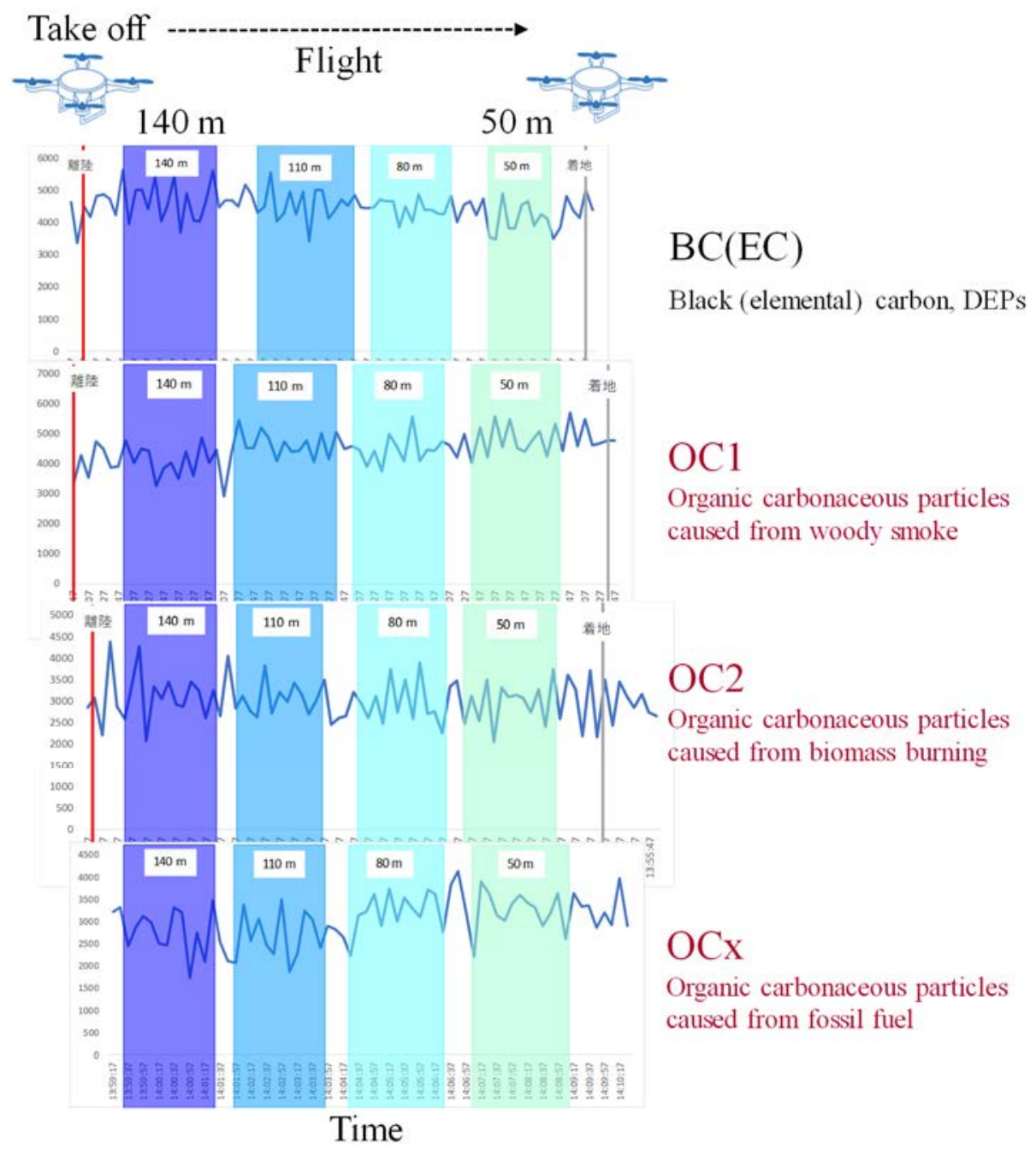

Figure 9: Real-time vertical distribution of $\mathrm{BC}$ and $\mathrm{OC} 1 \sim \mathrm{OCx}$ in $\mathrm{PM}_{2.5}$ determined by a MA 200 carbonaceous particle monitor during the sampling campaign period in 2018.

\section{CONCLUSION}

In this article, air quality measurement as $\mathrm{PM}_{2.5}$, ozone, black carbon caused by diesel exhaust particles and different carbonaceous particles from personal particles and gas sensors set in several UAVs were carried out. Air quality research is moving towards the more wide-spread use of UAVs to measure those pollutants at different altitudes; compare ground-based data; and autonomously track plumes emitted by combustion sources, revealing the origin of atmospheric pollutants. With the help of our developed UAVs, it is possible to investigate the spread mechanism of atmospheric pollutants, long range transportation, specification of the pollutant sources and the pollution mechanism with the vertical distribution in the lower boundary layer. 


\section{ACKNOWLEDGEMENTS}

This study was initiated by Saitama University and funded by the Saitama Prefectural Government of Japan accepted as the Saitama leading-edge industry design project (FY 2016 FY2018). Additional support was provided by the Special Funds of Grant-in-Aid for Scientific Research (B) (No. 24310005, FY 2012 FY2014; No. 15H05119, FY 2015 FY2017, No. 18H03384, FY 2018 FY2020) of the Japan Society for the Promotion of Science (JSPS) and Japanese Ministry of Education, Culture, Sports, Science and Technology (MEXT), Japan. The author also acknowledges research support by the Steel Foundation for Environmental Protection Technology of Japan (No. C-33, FY 2015- FY 2017). As this project leader, the author also would like to thank the members of our laboratory, Enroute Co., Ltd., Iyobeshoji Co., Ltd., Shibata Scientific Co., Ltd., and Japan Environmental Research Co., Ltd., Japan for their extensive efforts related to the study.

\section{REFERENCES}

[1] Arditsoglou, A. \& Samara, C., Levels of total suspended particulate matter and major trace elements in Kosovo: A source identification and apportionment study. Chemosphere, 59(5), pp. 669-678, 2005.

[2] Gong, X. et al., Size distribution of allergenic Cry j 2 released from airborne Cryptomeria japonica pollen grains during the pollen scattering seasons. Aerobiologia (International Journal of Aerobiology), 33(1), pp. 59-69, 2017.

[3] Lu, S. et al., Single particle aerosol mass spectrometry of coal combustion particles associated with high lung cancer rates in Xuanwei and Fuyuan, China. Chemosphere, 186, pp. 278-286, 2017.

[4] Xie, K., Li, W. \& Zhao, W., Coal chemical industry and its sustainable development in China. Energy, 35(11), pp. 4349-4355, 2010.

[5] Chow, J. C. \& Watson, J. G., Review of PM2.5 and PM10 apportionment for fossil fuel combustion and other sources by the chemical mass balance receptor model. Energy Fuels, 16(2), pp. 222-260, 2002.

[6] Wang, Q. et al., Studies on size distribution and health risk of 37 species of polycyclic aromatic hydrocarbons associated with fine particulate matters collected in the atmosphere of a suburban area of Shanghai city, China. Environmental Pollution, 214, pp. 149-160, 2016.

[7] Wang, Q., Itoh, S. \& Lu, S., Reduction of fine particles exhausted from small-size combustor using agricultural waste residue by controlling burning temperatures. International Journal of Sustainable Development and Planning, 9(5), pp. 717-726, 2014.

[8] Wang, Q., Otsuka, G., Dong, S., Ishihara, K., Lu, S. \& Sekiguchi, K., Study on the monitoring method for airborne herbaceous pollen in autumn by a mobile air sampler, Japanese Journal of Palynology, 61(2), pp. 49-55, 2016.

[9] Wang Q., Gong X., Suzuki M., Lu S., Sekiguchi K. \& Nakajima D., Size-segregated allergenic particles released from airborne Cryptomeria japonica pollen grains during the Yellow Sand events within the pollen scattering seasons. Asian Journal of Atmospheric Environment, 7(4), pp. 191-198, 2013.

[10] Weingartnera, E., Saathoffb, H., Schnaiterb, M., StreitaStreita, N., Bitnarc, B. \& Baltensperger, U., Absorption of light by soot particles: determination of the absorption coefficient by means of aethalometers, Journal of Aerosol Science, 34(10), pp. 1445-1463, 2003.

[11] Uematsu, M. et al., Atmospheric transport and deposition of anthropogenic substances from the Asia to the East China Sea. Marine Chemistry, 120(1), pp. 108-115, 2010. 